\title{
The Predictors study: Development and baseline characteristics of the Predictors 3 cohort
}

\author{
Yaakov Stern*, Yian Gu, Stephanie Cosentino, Martina Azar, Siobhan Lawless, \\ Oksana Tatarina \\ Cognitive Neuroscience Division, Department of Neurology, Columbia University College of Physicians and Surgeons, New York, NY, USA
}

\begin{abstract}
Introduction: The Predictors study was designed to predict the length of time to major disease outcomes in Alzheimer's disease (AD) patients. Here, we describe the development of a new, Predictors 3, cohort. Methods: Patients with prevalent or incident AD and individuals at-risk for developing AD were selected from the North Manhattan community and followed annually with instruments comparable to those used in the original two Predictors cohorts.

Results: The original Predictors cohorts were clinic based and racially/ethnically homogenous (94\% white, $6 \%$ black; $3 \%$ Hispanic). In contrast, the 274 elders in this cohort are community-based and ethnically diverse (39\% white, $40 \%$ black, $21 \%$ other; $78 \%$ Hispanic). Confirming previous observations, psychotic features were associated with poorer function and mental status and extrapyramidal signs with poorer function.

Discussion: This new cohort will allow us to test observations made in our original clinic-based cohorts in patients that may be more representative of the general community.

(C) 2016 the Alzheimer's Association. Published by Elsevier Inc. All rights reserved.
\end{abstract}

Keywords:

MCI; ADL; Cognitive function; Extrapyramidal signs; Psychotic features; Pharmacoeconomics; Prediction algorithms

\section{Introduction}

The ability to predict the length of time from disease onset to major disease outcomes such as the need for nursing home care or death in individual patients with Alzheimer's disease (AD) has implications for patient care, the development of interventions and public health. The major aim of the Predictors study has been to further the understanding of the natural history of AD to develop predictor algorithms that can accurately make these predictions.

The first two Predictors cohorts consisted of a total of 506 patients with mild AD drawn from memory disorder clinics at three AD research centers: Columbia University College of Physicians and Surgeons, Johns Hopkins University School of Medicine, and the Massachusetts General Hospi\footnotetext{
1838.

*Corresponding author. Tel.: +1-212-342-1350; Fax: +1-212-342-

E-mail address: ys11@columbia.edu
}

tal. Although relatively small by epidemiologic standards, the primary value of these cohorts has been the long-term acquisition of data at short intervals.

Data from the first two cohorts of the Predictors study have led to advances in clarifying the natural history of the disease [1-7] with regard to motor signs [8-11], psychiatric manifestations [12-17], imaging [18,19], function, and quality of life [20-27], genotype [28-30], medication use [31], economic burden [32-38], and clinico-pathologic relationships [39-42]. We have also developed several assessment tools that are in general use in clinical assessment and drug studies $[21,22,43]$.

Most notably, we recently developed [44] and validated [45] a new model of AD progression, which can be used to predict time to multiple disease endpoints. The analyses used a longitudinal form of the Grade of Membership (GoM) model $[46,47]$, which allows large amounts of data on individual patients collected over multiple visits to be efficiently and accurately summarized using a small number of distinct 
variables that represent the most salient characteristics of the AD process as it develops over time [48,49].

Despite the Predictors study's impact on our understanding of $\mathrm{AD}$ and its progression, the two patient cohorts were clinic based and racially/ethnically homogenous ( $94 \%$ white, $3 \%$ Hispanic). As clinical cohorts are not representative of the true distribution of the disease in the population, these studies are necessarily biased by the nature of the referral and recruitment patterns particular to the clinical setting. Furthermore, it is not known what proportion of patients with $\mathrm{AD}$ actually is seen in clinical settings. There have been very few studies examining the progression of $\mathrm{AD}$ in community populations or in patients where the date of disease onset is known.

The current article introduces a new Predictors 3 cohort, which was designed to remediate these drawbacks by recruiting a population-based, ethnically diverse cohort of patients, with an emphasis on those with incident AD. Recruitment of this cohort took advantage of the existing Washington Heights-Hamilton Heights-Inwood Columbia Aging Project (WHICAP), which for many years has followed random samples of elders in North Manhattan. From WHICAP, we identified elders with recent incident $\mathrm{AD}$ and recently identified prevalent $\mathrm{AD}$, as well as individuals at-risk for AD. At this point, we have recruited 274 elders into the Predictors 3 cohort and are following them annually with many of the same instruments included in the two original Predictors cohorts, as well as additional evaluations. This culturally and experientially diverse population provides a unique opportunity to assess a range of medical and sociocultural factors that may contribute to differential disease progression and specific outcomes.

This report is intended to describe the design and implementation of the Predictors 3 cohort and describe baseline subject population demographics. We also include some early cross-sectional observations that replicate observations in the previous two cohorts.

\section{Methods}

\subsection{Participant recruitment}

Our source of community-based subjects was the WHICAP cohort. All WHICAP participants were first identified from a random sample of elderly Medicare recipients residing in the designated areas of Washington Heights, Hamilton Heights, and Inwood in North Manhattan, NY. Potential participants were excluded at the time of recruitment if they did not speak English or Spanish. Prior analyses of the demographic characteristics indicate that WHICAP study participants are matched to U.S. Census data of older adults living in northern Manhattan with respect to age, years of education, race/ethnicity, and sex. The WHICAP participants were evaluated approximately every 18 months. WHICAP follows a combination of remaining participants from cohorts originally recruited in $1992(\mathrm{~N}=2332)$, between
1999 and $2001(\mathrm{~N}=2776)$, and 2009-2015 ( $\mathrm{N}=2088)$. Recruitment of the Predictors 3 cohort began in 2011.

\subsubsection{AD dementia}

Our primary goal was to recruit patients from WHICAP who were diagnosed with incident $\mathrm{AD}$ no earlier than 2 years before the start of the recruitment or at any subsequent time. To be considered an incident case or case with known onset, subjects had to have one or more initial WHICAP assessments in which they did not meet criteria for dementia followed by a subsequent assessment in which they met criteria for $\mathrm{AD}$. That visit when $\mathrm{AD}$ was first diagnosed constituted their initial Predictors 3 assessment. We also included patients with prevalent AD. These were WHICAP participants diagnosed with $\mathrm{AD}$ at their initial visit, which occurred within 2 years before the start of Predictors 3 recruitment. The diagnoses of $\mathrm{AD}$ are based on the recent 2011 criteria [50], and the Clinical Dementia Rating Scale (CDR) [51] is used to rate dementia severity.

\subsubsection{At-risk for $A D$}

We also enrolled subjects with a high probability of converting to $\mathrm{AD}$ over time as they were followed. This includes those participants with the diagnoses of mild cognitive impairment (MCI), which was based on the recent 2011 criteria [52]. In addition, we identified at-risk individuals the WHICAP algorithm for evaluating neuropsychological test scores. This algorithm uses a set of cut scores applied to the neuropsychological battery that are not norms based to determine whether an individual has sufficient cognitive deficit to meet criteria for dementia [53]. To do so, the individual must score below cut scores on two of three memory domains (immediate and delayed verbal recall and nonverbal recognition) as well as below cut scores on at least one test from two of the four other cognitive domains (orientation, language, reasoning, and visuospatial function). Individuals who algorithmically come close to meeting these cutpoints (e.g., meet only three of the four required cutpoints, but score close to the cutpoint on the fourth) are also flagged as at-risk for $\mathrm{AD}$, even if they do not meet formal criteria for MCI. These individuals have a high probability of converting to AD. Our reason for following at-risk individuals is to eventually enrich our pool of patient with incident dementia on subsequent visits, and then follow AD progression from its initial diagnosis. In addition, we eventually hope to extend our GoM model to individuals at-risk for developing AD.

Once a subject is included in the Predictors 3 cohort, they are followed annually. Participants' data at each assessment wave are reviewed in a consensus conference, where a new working diagnosis is established. Thus, we can ascertain if and when any of these at-risk individuals convert to AD.

\subsection{Schedule of assessments}

The following procedures are completed annually. A subset of the assessments is or can be conducted via informants. 
All assessment instruments are administered by bilingual psychometricians. The assessment battery is conducted in English and Spanish by balanced bilingual research staff. At baseline, participants are asked their opinion of which language would yield their best performance, and this language is used to administer the battery throughout all follow-up visits. All interview questions, test instructions, and stimuli have been translated into Spanish by a committee of Spanish speakers from Cuba, Puerto Rico, Spain, and the Dominican Republic, and then back-translated to ensure accuracy. Where necessary, scoring criteria are modified so that credit is given for responses that reflect regional idioms.

\subsubsection{Informant questionnaires}

Each participant in the Predictors study is required to have an informant. Informants are generally family members or home care paraprofessionals. For patients in nursing homes, clinical staff who have worked closely with the patient for at least 3 months are acceptable.

\subsubsection{Medical and neurological evaluation}

A semi-structured medical and neurological examination is administered. We collect a measure of body mass index (weight in kilogram/height in meter ${ }^{2}$ ) [54]. We document all past and current medical conditions, medical procedures, assistive devices obtained, and hospitalizations. The Rosen modification of the Hachinski Ischemic Scale score [55] is included as a measure of cerebrovascular disease and a potential predictive sign. Selected items from the Unified Parkinson's Disease Rating Scale [56-59] are used, comprising ratings of voice, facial immobility, resting tremor, rigidity (neck and each limb), brady/hypokinesia, posture, and gait. Severity of each sign is rated as either absent (0), slight (1), mild-moderate (2), marked (3), or severe (4). Having a moderate severity of at least one of these symptoms is considered as having moderate extrapyramidal signs (EPS). Reliability of this instrument has been established [9]. Signs are coded as idiopathic, probably induced by current neuroleptic medication use or possibly induced by previous use of neuroleptic medication. If signs are possibly or probably drug induced, then we consider them separately for analytic purposes. The presence and severity of myoclonus and other dyskinesias also are recorded.

A semi-structured interview captures nine key criteria for Lewy Body Dementia, which includes questions and probes regarding fluctuating cognition with pronounced variations in attention and alertness, visual hallucinations, parkinsonism, auditory, olfactory, or tactile hallucinations, repeated falls, syncope, transient alteration of consciousness, neuroleptic sensitivity, and systematized delusions. We include it to explore the predictive utility of these features in AD.

Comorbidities are systematically queried in the interview. We have typically summarized these with the Charlson index [60]. Now using cost linkage data, we can make use of the Elixhauser index [61], as it performs better in predicting health outcomes (e.g., mortality) with administrative claims data than the Deyo-Charlson method [61-64].

A standardized form is used to record medications, including medications prescribed or supplements taken for $\mathrm{AD}$ as well as vitamins. It records the medication name (which is subsequently coded), number of days the medication was taken during the study interval, total dose/day, and number of pills/day. Alcohol tobacco use is also recorded.

\subsubsection{MMSE and $m M M S$}

Global cognitive function is examined using the (Folstein) mini-mental state examination (MMSE) [65] as well as our 57-point version, the modified MMSE (mMMS) [66].

\subsubsection{Test for severe impairment}

To better assess cognition in the severe stages of dementia, patients scoring 30 points or less on the mMMS also receive the test for severe impairment [43,67]. It assesses six cognitive domains and presents tasks using simple onestep commands and nonverbal gestures.

\subsubsection{The clinical dementia rating scale}

The CDR is used to evaluate the patient at each measurement point to provide a global assessment of the severity of dementia [68].

\subsubsection{Functional ssessment}

Functional capacity is rated using the Blessed Dementia Rating Scale (Part 1) (BDRS [69]). We consider a score of 15 an endpoint for analysis. We have also developed subscores for the BDRS based on factor analysis [20]. The disability and functional limitation instrument is also administered [70,71].

\subsubsection{Neuropsychological test battery}

The neuropsychological test battery includes the following tests: Orientation: The 10 orientation items from the Mini-Mental State Examination [65]. Memory: Two tests are used: (1) Selective reminding test [72], (2) Benton visual retention test (BVRT) [73], Recognition Memory Multiple Choice version. Visuospatial ability: (1) Rosen Drawing Test [74], 5 selected items. (2) BVRT Matching, multiplechoice version. Language: (1) Naming. Boston Naming Test [75], 15 selected items. (2) Verbal fluency. The Controlled Word Association Test [76] and category naming: Animals, food, and clothing. (3) Comprehension. Complex ideational material subtest of the Boston Diagnostic Aphasia Evaluation (BDAE) [77]: first 6 items. (4) Repetition. High frequency items from the BDAE repetition of phrases subtest. Psychomotor speed: The Color Trails test [78] part 1 is administered. Executive functioning: (1) WAIS-R similarities [79]. (2) Color trails part 2. Raw scores and demographically corrected T-scores (age, years of education, sex, and ethnicity) are available. However, the primary measures we use in our analyses are 
neuropsychological factor scores derived from WHICAP data. The structure of the four-factor model and the magnitude of the relationship between the observed variables and the latent constructs are invariant across English and Spanish speakers [80]. The factors include memory, language, processing speed, and visual-spatial ability.

\subsubsection{Dependence scale}

This scale assesses the amount of assistance required by patients [21]. We typically use the sum of item scores for analysis. A dependence level can be derived from these items, ranging from 0 , totally independent, to 5 , totally dependent.

\subsubsection{Equivalent institutional care rating}

This rating records the rater's impression of the level of institutional care received by the patient, irrespective of the patient's actual location. Categories include limited home care, adult home (a supervised setting with regular assistance in most activities), and health-related facility [21].

\subsubsection{Psychiatric and behavioral changes}

We administer the neuropsychiatric interview [81]. In addition, the Columbia University Scale for Psychopathology in Alzheimer's Disease [12] is used to elicit information about symptoms of delusions, hallucinations, illusions, depressed mood, and other behavioral signs (wandering, verbal outbursts, physical threats and/or violence, agitation or restlessness, and nighttime confusion) occurring during the month before assessment.

Patient related past and current depressive symptoms are assessed. We use modified versions of the Patient Health Questionnaire-2 (PHQ) [82] and PHQ-9 [83] relating to past and current depression consistent with DSM-IV criteria. Informant-related depressive symptoms, relative to caregiving burden experienced within the past week, are assessed using the 10-item CES-D [84].

\subsubsection{Quality of life ratings}

We use our modified version of the Pleasant Events Schedule-AD [85] and the Apparent Emotion Scale to assess aspects of quality of life [22].

\subsubsection{Life-extending measures}

After a subject death, we record life-extending measures that caregivers may have chosen to request or withhold. These include administration of IV antibiotics or fluids, feeding tubes, or ventilatory support. We also note whether advanced care directives existed, or if a do not resuscitate order had been issued.

\subsubsection{Informal care}

In dementia, up to two-thirds of care is delivered by informal caregivers. The cost value of these services depends on both the amount of time caregivers provide services and the type of services provided. We have developed an instrument that captures "hands-on help" (help with the activities of daily living) as well as time spent supervising, cuing, or managing patient behavioral disturbances. We also have developed methodology to convert time to costs [36].

\subsubsection{Medicare and Medicaid claims data}

We obtained Medicare and Medicaid data (1999-2010) for the entire WHICAP cohort and the Predictors 3 cohort subset through the Research Data Assistance Center (ResDAC), a Center for Medicare and Medicaid Services contractor housed at the University of Minnesota. We currently plan to obtain SAFs and outpatient drug benefit (Part D) claims that are available for 2011-2013. A limitation to be kept in mind is that data from Medicare advantage participants are not available.

\section{Results}

The cohort consists of 274 community-based participants that represent all the incident and recent identified prevalent cases of $\mathrm{AD}$, and individuals at-risk of developing $\mathrm{AD}$ that were available over the present study period. Although we continue to recruit, we expect very few new participants. Demographics for each of the three subject groups are summarized in Table 1 . The participants self-identify as $39 \%$ white, $40 \%$ black or African American, and 21\% other; $78.4 \%$ are Hispanic/Latino. Educational attainment ranges from 0 to 20 years, but the mean for the cohort is 6.9 years of schooling.

Clinical features of Alzheimer's disease for each of the cohort subgroups are presented in Table 2. In general, the at-risk group shows the least severity or prevalence of each clinical feature, followed by the incident group and then the prevalent group. For example, mean MMSE was 15.6 in the prevalent group, 19.1 in the incident group and 22.7 in the at-risk group. Similarly, mean CDR was 1.23, 1.06, and .43 respectively across the prevalent, incident, and at-

Table 1

Demographic features of the Predictors 3 cohort

\begin{tabular}{|c|c|c|c|c|c|}
\hline & Prevalent AD & Incident AD & At-risk & Total & $P$ \\
\hline $\mathrm{N}$ & 46 & 109 & 119 & 274 & \\
\hline Age & $85.6(7.2)$ & $85.5(6.2)$ & $85.8(6.8)$ & $85.6(6.6)$ & .956 \\
\hline White/black/other, $n(\%)$ & $16 / 17 / 13(35 / 37 / 28)$ & $45 / 43 / 20(42 / 40 / 19)$ & $45 / 49 / 24(38 / 42 / 21)$ & $106 / 109 / 57(39 / 40 / 21)$ & .741 \\
\hline Female, $n(\%)$ & $37(80.4)$ & $90(82.6)$ & $86(72.3)$ & $213(77.7)$ & .156 \\
\hline Education (y) & $5.6(4.5)$ & $6.3(4.8)$ & $8.0(4.8)$ & $6.9(4.8)$ & .003 \\
\hline
\end{tabular}


Table 2

Clinical features of Alzheimer's disease in the three subject groups

\begin{tabular}{|c|c|c|c|c|}
\hline & $\begin{array}{l}\text { Prevalent } \\
\mathrm{AD}\end{array}$ & $\begin{array}{l}\text { Incident } \\
\mathrm{AD}\end{array}$ & At-risk & $P$ \\
\hline$N$ & 46 & 109 & 119 & - \\
\hline $\begin{array}{l}\text { Modified MMSE, } \\
\text { mean (SD) }\end{array}$ & $25.2(6.9)$ & $30.8(7.3)$ & $38.1(6.3)$ & $<.0001$ \\
\hline $\begin{array}{l}\text { Folstein MMSE score, } \\
\text { mean (SD) }\end{array}$ & $15.6(4.3)$ & $19.1(4.5)$ & $22.7(3.5)$ & $<.0001$ \\
\hline CES-D, mean (SD) & $3.6(2.1)$ & $3.0(1.5)$ & $3.4(1.6)$ & .092 \\
\hline $\begin{array}{l}\text { Dependence sum, } \\
\text { mean (SD) }\end{array}$ & $8(3.1)$ & $6.7(3.2)$ & $3.8(3.3)$ & $<.0001$ \\
\hline $\begin{array}{l}\text { Dependence level, } \\
\text { mean (SD) }\end{array}$ & $3.6(1.3)$ & $3.6(1.4)$ & $2.5(1.7)$ & $<.0001$ \\
\hline \multicolumn{5}{|l|}{$\begin{array}{l}\text { Equivalent institutional } \\
\text { care, } n(\%)\end{array}$} \\
\hline Limited home care & $6(13.6)$ & $31(29.8)$ & $76(65.5)$ & $<.0001$ \\
\hline Adult home & $24(54$ & $57(54.8)$ & $35(30.2)$ & \\
\hline Health-related facility & $14(31.8)$ & $16(15.4)$ & $5(4.3)$ & \\
\hline IADL, mean (SD) & $4.2(2.1)$ & $3.3(1.8)$ & $1.7(1.3)$ & $<.0001$ \\
\hline BADL, mean (SD) & $2.3(2)$ & $1.8(2.1)$ & $1.1(1.8)$ & .001 \\
\hline Delusion, $n(\%)$ & $28(60.9)$ & $59(57.3)$ & $35(30.2)$ & $<.0001$ \\
\hline Hallucination, $n(\%)$ & $15(32.6)$ & $27(26.2)$ & $18(15.5)$ & .035 \\
\hline Illusion, $n(\%)$ & $3(6.5)$ & $2(1.9)$ & $3(2.6)$ & .305 \\
\hline $\begin{array}{l}\text { Any psychiatric symptom, } \\
n(\%)\end{array}$ & $30(65.2)$ & $61(59.2)$ & $41(35.3)$ & $<.0001$ \\
\hline Moderate EPS, $n(\%)$ & $14(31.1)$ & $25(23.1)$ & $22(18.5)$ & .218 \\
\hline $\mathrm{CDR}$, mean $(\mathrm{SD})$ & $1.23(0.49)$ & $1.06(0.4)$ & $0.43(0.18)$ & $<.0001$ \\
\hline
\end{tabular}

Abbreviations: AD, Alzheimer disease; MMSE, mini-mental state examination; SD, standard deviation; EPS, extrapyramidal signs; CDR, Clinical Dementia Rating Scale.

risk groups. As two original Predictors cohorts used a strict MMSE cutpoint as one of the criteria for admission; here, we sought out as many incident and prevalent cases as we could identify within the 2 years before the initiation study and going forward. This resulted in patients who were primarily in the mild range of the disease, but some patients had a CDR score greater than one: 10 patients $(21.8 \%)$ in the prevalent group and seven patients $(6.4 \%)$ in the incident group.

Depressive affect, as measured by the PHQ or CES-D, was relatively low in all groups. Although all these participants lived at home at the baseline visit, a notable percentage of the patients with $\mathrm{AD}$ were reported to be receiving the equivalent of health-related facility care (i.e., an amount of care similar to that in a nursing home). As we have reported previously [12], simple delusions were quite prevalent in the AD patients with hallucinations and delusions less so.

We then investigated cross sectional associations with two clinical risk factors that have been reliably associated with poorer clinical outcomes: the presence of psychotic features and of moderate EPS. Here, we evaluated their association with cognition, measured by the MMSE and function as measured by the sum of IADL and BADL scores from the BDRS. As summarized in Table 3, in all three subgroups, the presence of psychotic features was associated with poorer ADL scores. Psychotic features were associated with poorer MMSE scores in the incident AD and at-risk groups; the difference was in the same direction but nonsig- nificant in the prevalent $\mathrm{AD}$ group. As summarized in Table 4, the presence of moderate EPS was associated with poorer $\mathrm{ADL}$ scores in the two $\mathrm{AD}$ groups but not in the at-risk individuals. No significant differences were noted for MMSE scores in patients with and without EPS.

\section{Discussion}

Here, we present the design and implementation of the new Predictors 3 cohort and describe the baseline subject population demographics and some early cross-sectional observations. This cohort differs from the previous two Predictors study cohorts in that it is community-based and strongly multiethnic. In addition, although the previous two cohorts consisted of patients who had mild-prevalent $\mathrm{AD}$ at baseline, this cohort also includes individuals at-risk for $\mathrm{AD}$, as well as incident cases where the date of onset is relatively fixed. Despite these differences, we have retained most of the evaluation instruments from the previous two cohorts. This should allow us to determine whether the observations that we have made on these clinic-based cohorts remain valid.

We believe that the Predictors 3 cohort is more representative of the larger population of individuals with $\mathrm{AD}$ because it is drawn from the community and clinic based as were the initial two cohorts. On the other hand, the Washington Heights-Inwood community of Northern Manhattan is predominantly Hispanic, and $70 \%$ of the cohort has 8 or fewer years of schooling. It therefore may not be representative of community-based $\mathrm{AD}$ patients in general. Long-term

Table 3

Relation of presence or absence of psychiatric symptoms to cognition (MMSE) and function (ADL)

\begin{tabular}{|c|c|c|c|}
\hline & \multicolumn{2}{|c|}{ Psychotic features } & \multirow[b]{2}{*}{$P$} \\
\hline & No & Yes & \\
\hline \multicolumn{4}{|l|}{ Prevalent AD } \\
\hline \multicolumn{4}{|l|}{ MMSE } \\
\hline Number & 16 & 30 & \\
\hline Mean (SD) & $17.0(4.1)$ & $14.9(4.3)$ & .117 \\
\hline \multicolumn{4}{|l|}{$\mathrm{ADL}$} \\
\hline Number & 16 & 30 & \\
\hline Mean (SD) & $4.8(3.4)$ & $7.5(2.9)$ & .007 \\
\hline \multicolumn{4}{|l|}{ Incident AD } \\
\hline \multicolumn{4}{|l|}{ MMSE } \\
\hline Number & 40 & 59 & \\
\hline Mean (SD) & $20.4(4.1)$ & $18.2(4.5)$ & .017 \\
\hline \multicolumn{4}{|l|}{ ADL } \\
\hline Number & 41 & 61 & \\
\hline Mean (SD) & $4.6(3.1)$ & $5.8(3.4)$ & .074 \\
\hline \multicolumn{4}{|l|}{ At-risk } \\
\hline \multicolumn{4}{|l|}{ MMSE } \\
\hline Number & 73 & 41 & \\
\hline Mean (SD) & $23.1(3.4)$ & $21.8(3.4)$ & .065 \\
\hline \multicolumn{4}{|l|}{ ADL } \\
\hline Number & 74 & 41 & \\
\hline Mean (SD) & $2.1(2.4)$ & $4.1(2.8)$ & .001 \\
\hline
\end{tabular}

Abbreviations: AD, Alzheimer disease; MMSE, mini-mental state examination; $\mathrm{SD}$, standard deviation. 
Table 4

Relation of presence or absence of moderate extrapyramidal signs to cognition (MMSE) and function (ADL)

\begin{tabular}{|c|c|c|c|}
\hline & \multicolumn{2}{|c|}{ Moderate EPS } & \multirow[b]{2}{*}{$P$} \\
\hline & No & Yes & \\
\hline \multicolumn{4}{|l|}{ Prevalent AD } \\
\hline \multicolumn{4}{|l|}{ MMSE } \\
\hline Number & 31 & 14 & \\
\hline Mean (SD) & $15.3(4.5)$ & $16.4(3.9)$ & .440 \\
\hline \multicolumn{4}{|l|}{$\mathrm{ADL}$} \\
\hline Number & 31 & 14 & \\
\hline Mean (SD) & $5.8(3.2)$ & $8.1(3.5)$ & .036 \\
\hline \multicolumn{4}{|l|}{ Incident AD } \\
\hline \multicolumn{4}{|l|}{ MMSE } \\
\hline Number & 80 & 24 & \\
\hline Mean (SD) & $19.1(4.5)$ & $19.1(4.5)$ & .978 \\
\hline \multicolumn{4}{|l|}{ ADL } \\
\hline Number & 83 & 24 & \\
\hline Mean (SD) & $4.8(2.9)$ & $6.6(4.4)$ & .016 \\
\hline \multicolumn{4}{|l|}{ At-risk } \\
\hline \multicolumn{4}{|l|}{ MMSE } \\
\hline Number & 95 & 22 & \\
\hline Mean (SD) & 22.5 (3.6) & $23.7(2.9)$ & .137 \\
\hline \multicolumn{4}{|l|}{ ADL } \\
\hline Number & 95 & 22 & \\
\hline Mean (SD) & $2.8(2.7)$ & $2.6(2.7)$ & .753 \\
\hline
\end{tabular}

Abbreviations: AD, Alzheimer disease; MMSE, mini-mental state examination; $\mathrm{SD}$, standard deviation.

follow-up of this cohort will provide important data about the natural history of Alzheimer's disease this understudied group.

We required that each participant in the study have an informant. This could impact on generalizability. The "workload" for each study participant is relatively comparable to that in our previous studies. A large degree of the evaluation is completed by the informant, reducing burden on the patient. We continue using the quality of life instruments from the first two Predictors cohorts. We are aware that these instruments do not correspond to those used in current clinical trials, but they provide important quality of life information.

Despite the differences between the current and previous cohorts, preliminary baseline analyses showed a relationship between the presence or absence of extrapyramidal signs and psychotic features and severity of the disease as measured by either a mental status test or functional scale, as we have previously reported in the earlier cohorts [14]. In the clinicbased cohorts, we have shown that these disease features are predictive of the future course of the disease [2,5]. These features are also components of the grade of membership model of AD progression that was developed based on patients in the Predictors 1 cohort [44]. When applied to the Predictors 2 cohort data, a prediction algorithm based on this model showed excellent accuracy in predicting time to nursing home admission, equivalent nursing home care or death [45].

As mentioned above, the Predictors study is developing algorithms to predict time until important disease endpoints.
To date, we have considered nursing home entry, the need for nursing home care, and death, as well as cut scores on both the MMSE and BDRS. The grade of membership model that we have developed is capable of predicting time until any value of any of the measures in the model, such as time until a specific score on the scale, or until a specific item on the scale is endorsed. Accurate prediction of time until endpoints provides a service to patients, families, and physicians. It also could aid in the assignment of patients to arms of clinical trials and in economic modeling of the disease.

One of our goals is to extend the present grade of membership model to this community-based population to determine whether it truly models the progression of $\mathrm{AD}$ in non-clinic-based patients. Presence of at-risk subjects will eventually allow us to extend the model to the preclinical stage. The availability of Medicare/Medicaid linkage data will allow us to generate important observations about the relationship between various aspects of the disease and cost. We hope that over time analyses of follow-up data from this cohort will contribute to the understanding of the natural history and risk factors for progression of $\mathrm{AD}$ to the same level as the previous two Predictors cohorts.

\section{Acknowledgments}

This work was supported by R01 AG07370 from the National Institute on Aging (PI, Dr Stern).

\section{RESEARCH IN CONTEXT}

1. Systematic review: Data from the first two cohorts of the Predictors study has led to advances in our understanding of the natural history of Alzheimer's disease (AD) and has resulted in algorithms for predicting time to important disease endpoints in individual patients. However, the patients in these studies were clinic-based and almost all White.

2. Interpretation: We therefore have recruited a new, Predictors 3 cohort that is population-based and ethnically diverse. Our aim is to attempt to replicate and expand on our previous observations in a cohort that may be more representative of $\mathrm{AD}$ in the community. Already in our baseline data, we replicate our previous observation that two clinical features, extrapyramidal signs and psychotic features are associated with more severe disease presentation.

3. Future direction: Our hope is that analysis of followup data will increase our understanding of the natural history and risk factors for the progression of $\mathrm{AD}$ in this ethnically diverse, population-based cohort. 


\section{References}

[1] Stern Y, Folstein M, Albert M, Richards M, Miller L, Bylsma F, et al. Multicenter study of predictors of disease course in Alzheimer disease (the "Predictors Study"). I. Study design, cohort description, and intersite comparisons. Alzheimer Dis Assoc Disord 1993;7:3-21.

[2] Stern Y, Albert M, Brandt J, Jacobs DM, Tang MX, Marder K, et al. Utility of extrapyramidal signs and psychosis as predictors of cognitive and functional decline, nursing home admission, and death in Alzheimer's disease: prospective analyses from the Predictors Study. Neurology 1994;44:2300-7.

[3] Jacobs D, Sano M, Marder K, Bell K, Bylsma F, Lafleche G, et al. Age at onset of Alzheimer's disease: relation to pattern of cognitive dysfunction and rate of decline. Neurology 1994;44:1215-20.

[4] Stern Y, Liu X, Albert M, Brandt J, Jacobs DM, CastilloCastenada CD, et al. Modeling the influence of extrapyramidal signs on the progression of Alzheimer's disease. Arch Neurol 1996; 53:1121-6.

[5] Stern Y, Tang MX, Albert MS, Brandt J, Jacobs DM, Bell K, et al. Predicting time to nursing home care and death in individuals with Alzheimer disease. J Am Med Assoc 1997;277:806-12.

[6] Holtzer R, Wegesin DJ, Albert SM, Marder K, Bell K, Albert M, et al. The rate of cognitive decline and risk of reaching clinical milestones in Alzheimer's disease. Arch Neurol 2003;60:1137-42.

[7] Stallard E, Sloan F. Analysis of the natural history of dementia using longitudinal grade of membership models. In: Yashin AI, Stallard E, Land KC (eds). Biodemography of Aging: Determinants of Healthy Life Span and Longevity New York: Springer.

[8] Chen JY, Stern Y, Sano M, Mayeux R. Cumulative risks of developing extrapyramidal signs, psychosis, or myoclonus in the course of Alzheimer's disease. Arch Neurol 1991;48:1141-3.

[9] Richards M, Marder K, Bell K, Dooneief G, Mayeux R, Stern Y. Interrater reliability of extrapyramidal signs in a group assessed for dementia. Arch Neurol 1991;48:1147-9.

[10] Scarmeas N, Hadjigeorgiou GM, Papadimitriou A, Dubois B, Sarazin M, Brandt J, et al. Motor signs during the course of Alzheimer disease. Neurology 2004;63:975-82.

[11] Scarmeas N, Albert M, Brandt J, Blacker D, Hadjigeorgiou G, Papadimitriou A, et al. Motor signs predict poor outcomes in Alzheimer disease. Neurology 2005;64:1696-703.

[12] Devanand DP, Miller L, Richards M, Marder K, Bell K, Mayeux R, et al. The Columbia University Scale for Psychopathology in Alzheimer's disease. Arch Neurol 1992;49:371-6.

[13] Bylsma FW, Folstein MF, Devanand DP, Richards M, Bello J, Albert M, et al. Delusions and patterns of cognitive impairment in Alzheimer's disease. Neuropsyhiatry Neuropsychol Behav Neurol 1994; 7:98-103.

[14] Devanand D, Jacobs DM, Tang MX, Castillo-Castenada CD, Sano M, Marder K, et al. The course of psychopathological features in mild to moderate Alzheimer's disease. Arch Gen Psychiatry 1997;54:257-63.

[15] Holtzer R, Tang MX, Devanand DP, Albert SM, Wegesin DJ, Marder K, et al. Psychopathologic features in Alzheimer's disease: Course and relation to cognitive status. J Am Geriatr Soc 2003; 51:953-60.

[16] Scarmeas N, Brandt J, Albert M, Hadjigeorgiou G, Papadimitriou A, Dubois B, et al. Delusions and hallucinations are associated with worse outcome in Alzheimer disease. Arch Neurol 2005;62:1601-8.

[17] Holtzer R, Scarmeas N, Wegesin DJ, Albert M, Brandt J, Dubois B, et al. Depressive symptoms in Alzheimer's disease: Natural course and temporal relation to function and cognitive status. J Am Geriatr Soc 2005;53:2083-9.

[18] Marder K, Richards M, Bello J, Bell K, Sano M, Miller L, et al. Clinical correlates of Alzheimer's disease with and without silent radiographic abnormalities. Arch Neurol 1995;52:146-51.

[19] Brickman AM, Honig LS, Scarmeas N, Tatarina O, Sanders L, Albert MS, et al. Measuring cerebral atrophy and white matter hyper- intensity burden to predict the rate of cognitive decline in Alzheimer disease. Arch Neurol 2008;65:1202-8.

[20] Stern Y, Hesdorffer D, Sano M, Mayeux R. Measurement and prediction of functional capacity in Alzheimer's disease. Neurology 1990; 40:8-14.

[21] Stern Y, Albert SM, Sano M, Richards M, Miller L, Folstein M, et al. Assessing patient dependence in Alzheimer's disease. J Gerontol 1994;49:M216-22.

[22] Albert SM, Del Castillo-Castaneda C, Sano M, Jacobs DM, Marder K, Bell K, et al. Quality of life in patients with Alzheimer's disease as reported by patient proxies. J Am Geriatr Soc 1996;44:1342-7.

[23] Albert SM, Castillo-Castaneda C, Jacobs DM, Sano M, Bell K, Merchant C, et al. Proxy-reported quality of life in Alzheimer's patients: Comparison of clinical and population-based samples. J Ment Health Aging 1999;5:49-58.

[24] Albert SM, Castillo-Castaneda C, Jacobs DM, Sano M, Marder K, Bell K, et al. Longitudinal study of quality of life in people with advanced Alzheimer's disease. Am J Geriatr Psychiatry 2001;9:160-8.

[25] Brickman AM, Riba A, Bell K, Marder K, Albert M, Brandt J, et al. Longitudinal assessment of patient dependence in Alzheimer's disease. Arch Neurol 2002;59:1304-8.

[26] Scherer RK, Scarmeas N, Brandt J, Blacker D, Albert MS, Stern Y. The relation of patient dependence to home health aide use in Alzheimer's disease. J Gerontol A Biol Sci Med Sci 2008;63:1005-9.

[27] Siedlecki KL, Tatarina O, Sanders L, Albert M, Blacker D, Dubois B, et al. Comparison of patient and caregiver reports of patient activity participation and its relationship to mental health in patients with Alzheimer's disease. J Gerontol B Psychol Sci Soc Sci 2009;64:687-95.

[28] Stern Y, Brandt J, Albert M, Jacobs DM, Bell K, Marder K, et al. The absence of an apolipoprotein e4 allele is associated with a more aggressive form of Alzheimer's disease. Ann Neurol 1997;41:615-20.

[29] Scarmeas N, Brandt J, Albert M, Devanand DP, Marder K, Bell K, et al. Association between the APOE genotype and psychopathologic symptoms in Alzheimer's disease. Neurology 2002;58:1182-8.

[30] Cosentino S, Scarmeas N, Helzner E, Glymour MM, Brandt J, Albert M, et al. APOE epsilon 4 allele predicts faster cognitive decline in mild Alzheimer disease. Neurology 2008;70:1842-9.

[31] Zhu CW, Livote EE, Kahle-Wrobleski K, Scarmeas N, Albert M, Brandt J, et al. Longitudinal medication usage in Alzheimer disease patients. Alzheimer Dis Assoc Disord 2010;24:354-9.

[32] Zhu CW, Leibman C, McLaughlin T, Scarmeas N, Albert M, Brandt J, et al. The effects of patient function and dependence on costs of care in Alzheimer's disease. J Am Geriatr Soc 2008;56:1497-503.

[33] Zhu CW, Leibman C, McLaughlin T, Zbrozek AS, Scarmeas N, Albert M, et al. Patient dependence and longitudinal changes in costs of care in Alzheimer's disease. Dement Geriatr Cogn Disord 2008; 26:416-23.

[34] Zhu CW, Leibman C, Townsend R, McLaughlin T, Scarmeas N, Albert M, et al. Bridging from clinical endpoints to estimates of treatment value for external decision makers. J Nutr Health Aging 2009; 13:256-9.

[35] Zhu CW, Scarmeas N, Torgan R, Albert M, Brandt J, Blacker D, et al. Longitudinal study of effects of patient characteristics on direct costs in Alzheimer disease. Neurology 2006;67:998-1005.

[36] Zhu CW, Scarmeas N, Torgan R, Albert M, Brandt J, Blacker D, et al. Clinical characteristics and longitudinal changes of informal cost of Alzheimer's disease in the community. J Am Geriatr Soc 2006; 54:1596-602.

[37] Zhu CW, Scarmeas N, Torgan R, Albert M, Brandt J, Blacker D, et al. Clinical features associated with costs in early AD: baseline data from the Predictors Study. Neurology 2006;66:1021-8.

[38] Zhu CW, Torgan R, Scarmeas N, Albert M, Brandt J, Blacker D, et al. Home health and informal care utilization and costs over time in Alzheimer's disease. Home Health Care Serv Q 2008;27:1-20.

[39] Liu Y, Stern Y, Chun M, Jacobs DM, Yau P, Goldman JR. Pathological correlates of extrapyramidal signs in Alzheimer's disease. Ann Neurol 1997;41:368-74. 
[40] Stern Y, Jacobs D, Goldman J, Gomez-Tortosa E, Hyman BT, Liu Y, et al. An investigation of clinical correlates of Lewy bodies in autopsy proven Alzheimer's disease. Arch Neurol 2001;58:460-5.

[41] Holtzer R, Irizarry MC, Sanders J, Hyman BT, Wegesin DJ, Riba A, et al. Relation of quantitative indexes of concurrent alpha-synuclein abnormalities to clinical outcome in autopsy-proven Alzheimer disease. Arch Neurol 2006;63:226-30.

[42] Steinerman JR, Irizarry M, Scarmeas N, Raju S, Brandt J, Albert $\mathrm{M}$, et al. Distinct pools of beta-amyloid in Alzheimer disease-affected brain: a clinicopathologic study. Arch Neurol 2008;65:906-12.

[43] Jacobs DM, Albert SM, Sano M, Del Castillo-Castaneda C, Paik MC, Marder K, et al. Assessment of cognition in advanced AD: the test for severe impairment. Neurology 1999;52:1689-91.

[44] Stallard E, Kinosian B, Zbrozek AS, Yashin AI, Glick HA, Stern Y. Estimation and validation of a multiattribute model of Alzheimer disease progression. Med Decis Making 2010;30:625-38.

[45] Razlighi QR, Stallard E, Brandt J, Blacker D, Albert M, Scarmeas N, et al. A new algorithm for predicting time to disease endpoints in Alzheimer's disease patients. J Alzheimers Dis 2014;38:661-8.

[46] Kinosian BP, Stallard E, Lee JH, Woodbury MA, Zbrozek AS, Glick HA. Predicting 10-year care requirements for older people with suspected Alzheimer's disease. J Am Geriatr Soc 2000; 48:631-8.

[47] Stallard E. Trajectories of morbidity, disability, and mortality among the U.S. elderly population: Evidence from the 1984-1999 NLTCS. North Am Actuarial J 2007;11:16-53.

[48] Woodbury MA, Clive J. Clinical pure types as a fuzzy partition. J Cybernetics 1974;4:111-21.

[49] Fillenbaum G, Woodbury MA. Typology of Alzheimer's disease: Findings from CERAD data. Aging Ment Health 1998;2:105-27.

[50] McKhann GM, Knopman DS, Chertkow H, Hyman BT, Jack CR Jr, Kawas CH, et al. The diagnosis of dementia due to Alzheimer's disease: recommendations from the National Institute on Aging-Alzheimer's Association workgroups on diagnostic guidelines for Alzheimer's disease. Alzheimers Dement 2011;7:263-9.

[51] Berg L. Clinical Dementia Rating (CDR). Psychopharmacol Bull 1988;24:637-9.

[52] Albert MS, DeKosky ST, Dickson D, Dubois B, Feldman HH, Fox NC, et al. The diagnosis of mild cognitive impairment due to Alzheimer's disease: recommendations from the National Institute on Aging-Alzheimer's Association workgroups on diagnostic guidelines for Alzheimer's disease. Alzheimers Dement 2011;7:270-9.

[53] Stern Y, Andrews H, Pittman J, Sano M, Tatemichi T, Lantigua R, et al. Diagnosis of dementia in a heterogeneous population. Development of a neuropsychological paradigm-based diagnosis of dementia and quantified correction for the effects of education. Arch Neurol 1992; 49:453-60.

[54] Mueller WH, Wear ML, Hanis CL, Emerson JB, Barton SA, HewettEmmett D, et al. Which measure of body fat distribution is best for epidemiologic research? AM J Epidemiol 1991;133:858-69.

[55] Rosen WG, Terry RD, Fuld PA, Katzman R, Peck A. Pathological verification of ischemic score in differentiation of dementias. Ann Neurol 1980; 7:486-8.

[56] Stern MB, Hurting HI. The clinical characteristics of Parkinson's disease and Parkinsonian syndromes: diagnosis and assessment. The Comprehensive Management of Parkinson's Disease. New York NY: PMA Corp.; 1978. p. 3-50.

[57] Goetz CG, Stebbins GT, Chmura TA, Fahn S, Klawans HL, Marsden CD. Teaching tape for the motor section of the Unified Parkinson's disease rating scale. Mov Disord 1995;10:263-6.

[58] Louis ED, Lynch T, Marder K, Fahn S. Reliability of patient completion of the historical section of the Unified Parkinson's Disease Rating Scale. Mov Disord 1996;11:185-92.

[59] Richards M, Marder K, Cote L, Mayeux R. Interrater reliability of the Unified Parkinson's Disease Rating Scale motor examination. Mov Disord 1994;9:89-91.
[60] Charlson ME, Pompei P, Ales KL, MacKenzie CR. A new method of classifying prognostic comorbidity in longitudinal studies: development and validation. J Chronic Dis 1987:40:373-83.

[61] Elixhauser A, Steiner C, Harris DR, Coffey RM. Comorbidity measures for use with administrative data. Med Care 1998;36:8-27.

[62] Chu YT, Ng YY, Wu SC. Comparison of different comorbidity measures for use with administrative data in predicting short-term and long-term mortality. BMC Health Serv Res 2010;10:140.

[63] Dominick KL, Dudley TK, Coffman CJ, Bosworth HB. Comparison of three comorbidity measures for predicting health service use in patients with osteoarthritis. Arthritis Rheum 2005;53:666-72.

[64] Farley JF, Harley CR, Devine JW. A comparison of comorbidity measurements to predict healthcare expenditures. Am J Manag Care 2006; 12:110-9.

[65] Folstein MF, Folstein SE, McHugh PR. 'Mini-mental State': A practical method for grading the cognitive state of patients for the clinician. J Psychiatr Res 1975;12:189-98.

[66] Stern Y, Sano M, Paulson J, Mayeux R. Modified mini-mental state examination: Validity and reliability. Neurology 1987;37:179.

[67] Albert M, Cohen C. The Test for Severe Impairment: An instrument for the assessment of patients with severe cognitive dysfunction. J Am Geriatr Soc 1992;40:449-53.

[68] Hughes CP, Berg L, Danziger WL, Coben LA, Martin RL. A new clinical scale for the staging of dementia. Br J Psychiatry 1982; 140:566-72.

[69] Blessed G, Tomlinson BE, Roth M. The association between quantitative measures of senile change in the cerebral grey matter of elderly subjects. Br J Psychol 1968;114:797-811.

[70] Gurland B, Kuriansky J, Sharpe L, Simon R, Stiller P, Birkett P. The Comprehensive assessment and Referral Evaluation (CARE)-rationale, development and reliability. Int J Aging Hum Dev 1977;8:9-42.

[71] Golden RR, Teresi JA, Gurland BJ. Development of indicator scales for the Comprehensive Assessment and Referral Evaluation (CARE) interview schedule. J Gerontol 1984:39:138-46.

[72] Buschke H, Fuld PA. Evaluating storage, retention, and retrieval in disordered memory and learning. Neurology 1974;24:1019-25.

[73] Benton A. The Visual Retention Test. New York: The Psychological Corp; 1955.

[74] Rosen W. The Rosen Drawing Test. Bronx, NY: Veterans Administration Medical Center; 1981.

[75] Kaplan E, Goodglass H, Weintraub S. Boston Naming Test. Philadelphia, PA: Lea \& Febiger; 1983.

[76] Benton AL, Hamsher K, Sivan AB. Multilingual Aphasia Examination. Iowa City: AJA Associates, Inc; 1994.

[77] Goodglass H, Kaplan D. The assessment of Aphasia and Related Disorders. 2nd ed. Philadelphia: Lea \& Febiger; 1983.

[78] D'Elia LF, Satz P, Uchiyama CL, White T. Color Trails Test Professional Manual. Odessa, FL: Psychological Assessment Resources; 1994.

[79] Wechsler D. Wechler Adult Intelligence Scale Revised. New York: The Psychological Corp; 1981.

[80] Siedlecki KL, Manly JJ, Brickman AM, Schupf N, Tang MX, Stern Y. Do neuropsychological tests have the same meaning in Spanish speakers as they do in English speakers? Neuropsychology 2010;24:402-11.

[81] Cummings J, Mega M, Gray K, Rosenberg-Thompson S, Carusi D, Gornbein J. The Neuropsychiatric Inventory: comprehensive assessment of psychopathology in dementia. Neurology 1994;44:2308-14.

[82] Kroenke K, Spitzer RL, Williams JB. The Patient Health Questionnaire-2: validity of a two-item depression screener. Med Care 2003;41:1284-92.

[83] Kroenke K, Spitzer RL, Williams JB. The PHQ-9: validity of a brief depression severity measure. J Gen Intern Med 2001;16:606-13.

[84] Radloff LL. The CES-D: A self-report depression scale for research in the general population. Appl Psychol Meas 1977;1:385-401.

[85] Teri L, Logsdon RG. Identifying pleasant activities for Alzheimer's disease patients: The Pleasant Events Schedule-AD. Gerontologist 1991;31:124-7. 